\title{
Repression of Lignin Synthesis in Rice by C4H and 4CL Using RNAi
}

\author{
Xia Gengshou
}

\begin{abstract}
Cinnamate-4-hydroxylase $\quad(\mathrm{C} 4 \mathrm{H}) \quad$ and 4-hydroxycinnamate CoA ligase (4CL) are two enzymes envolved in Phenylpropanoid synthesis pathway from lignin. They catalyze hydroxy-L-phenylalanine into cinnamic acid and coenzyme A esters. This paper constructs RNA interference vectors of $\mathrm{C4H}$ and $4 \mathrm{CL}$ genes, transforms "Zhonghua 11", a rice variety into single-gene $\mathrm{C} 4 \mathrm{H}$ and $4 \mathrm{CL}$ and double-gene C4HL transgenic plants using Agrobacterium mediation. By measuring the lignin content in the straw of mature $T_{0}$ generation transgenic rice plant, it shows that lignin content in transgenic plants is lower than that of non-transgenic ones. According to semi-quantitative RT-PCR analysis of $T_{1}$ generation, $\mathrm{C} 4 \mathrm{H}$ and $4 \mathrm{CL}$ gene expressions in transgene-positive plants are significantly lower than those of wild type. $\mathrm{C} 4 \mathrm{H}$ transgenic rice plant has lower lignin content but does not affect normal field agronomic traits. The study provides reference for comprehensive utilization of rice straw.
\end{abstract}

Index Terms-Agrobacterium transformation, lignin, rice, RNA interference.

\section{INTRODUCTION}

As nature's highest-yielding organic substance only second to cellulose, lignin is a complex phenolic polymer of four alcohol monomers (Coumadin alcohol, coniferyl alcohol, 5 - hydroxy coniferyl alcohol, mustard alcohol) polymerized by over 20 chemical bonds. Due to the constraints of its structure and the current utilization capacity, although lignin possesses a large natural reserve and a growth speed of 50 billion tons per year, so far more than $95 \%$ of lignin fails to be effectively utilized. Instead, it is discharged into river as "black liquor" or burned after concentration [1]. People have been exploring a transgenic method to repress lignin biosynthesis, in order to resolve its environmental pollution from the root. Currently the method of crop straw fermentation to produce fuel ethanol is one of the hot research topics around the world.

The research on lignin biosynthesis and its molecular regulation has made rapid progress. Lignin can enhance the mechanical strength of plant cells and tissues and prevent pathogenic bacteria invasion. Therefore, inhibition of lignin synthesis must be appropriate; otherwise it will affect the growth and development of plants. For molecular regulation of lignin synthesis, caffeic acid/5-hydroxy-ferulic acid-O-methyltransferase (COMT), caffeoyl coenzyme A

Manuscript received December 20, 2012; revised February 26, 2013. This work was supported by Science and Technology Project of Lishui City, Zhejiang (YL200735007, 2010JYZB08); and Natural Science Foundation of Zhejiang, China (LY12C14003).

Xia Gengshou is with the Lishui University, Lishui, Zhejiang, China (e-mail: lsxyxgs@163.com).
O-methyltransferase (CCOMT), ferulic acid 5-hydroxylase $(\mathrm{F} 5 \mathrm{H})$, cinnamic acid coenzyme A reductase (CCR) and cinnamic alcohol dehydrogenase (CAD) can regulate lignin synthesis, so that suppressing the expression of these genes will affect lignin monomer composition and lignin content [2], [3]. However, cinnamic acid 4-hydroxylase (C4H) and 4coumarate coenzyme A ligase (4CL) are two enzymes involved in the phenylpropane synthesis in which they catalyze phenylalanine into hydroxycinnamic acid and its coenzyme A esters. Amongst the inhibition of 4CL gene expression will reduce the synthesis of $\mathrm{H}, \mathrm{G}$ and S-type lignin. Therefore, genetic engineering can be utilized to suppress $\mathrm{C} 4 \mathrm{H}$ and $4 \mathrm{CL}$ gene expressions and consequently reduce lignin content in the straw of gramineous plants [4], [5].

The study shows that RNA interference (RNAi) exerts significant inhibitive effect on plant gene expression, and it is a commonly used method to artificially control gene expression. This study constructs RNA hairpin structured (hpRNA) RNAi vector by use of $\mathrm{C} 4 \mathrm{H}$ and 4CL genes, and it loads the vector with forward and reverse segments of target gene to transform rice plant by Agrobacterium, so that the plant can transcribe and process siRNA, which can degrade endogenous or homologous genes, and eventually reduce or prevent the expression of these genes. In this way, transgenic rice plants with normal phenotype and low lignin content can be identified and they act as the parent for low-lignin crop breeding.

\section{MATERIALS AND METHODS}

\section{A. Materials}

Japonica rice varieties (Oryza sativa L subsp.japonica): "Nipponbare" and "Zhonghua 11" saved in laboratory. DNA and RNA were extracted from leaves in the seedling stage for detection.

\section{B. The Construction of RNAi Vector for Lignin Biosynthetic Regulatory Genes C4H1, 4CL6 and C4HL}

Homologous analysis was carried out on the amino acid sequences coded by $\mathrm{C} 4 \mathrm{H}$ and 4CL genes listed in GenBank by DNAMAN software, and then specific primers were designed to amplify $\mathrm{C} 4 \mathrm{H}$ and $4 \mathrm{CL}$ gene fragments so as to construct C4H1, 4CL6 and C4HL RNAi vector.

\section{Agrobacterium-Mediated Transformation of Rice Plant}

Hiei's Agrobacterium transformation method [6] was adopted.

\section{Detection of $T_{0}$ Generation Transgenic Rice Plant}

Plant height and number of tillers were measured in field, 
and then plants were harvested from the roots, taken back to the laboratory, and dried at room temperature after measuring panicle length and striping spike,. After that, grain number per plant, thousand seed weight and straw dry weight were measured. Current commonly-used lignin detection methods were reviewed and detection object and lab conditions were considered so as to determine an appropriate method. First, the Klason method was used, but the operation easily produced losses and affected results. Therefore, after referring to the method of Li Jing et al to measure lignin in ginseng, the classical Klason method and ultraviolet spectrophotometry were combined to constitute the detection method of this study.

\section{E. Detection of $T_{1}$ Generation Transgenic Rice Plant}

When seedlings grew into about two leaves and one heart, tender leaf was taken and the actin gene acted as internal control (Act-F and Act-R as primer) for RT-PCR (reverse transcription PCR). By this method, the expression of single gene $4 \mathrm{CL}$ and $\mathrm{C} 4 \mathrm{H}$ and double gene $\mathrm{C} 4 \mathrm{HL}$ in transgenic plants were detected.

\section{RESULTS}

\section{A. Analysis of Agronomic Traits of Transgenic Rice and Contrast of Field Growth Conditions}

According to the experimental purposes, 10 numbered single plants ( $8 \mathrm{C} 4 \mathrm{HL}$ plants and 8 control plants) from $\mathrm{T}_{0}$ generation were randomly selected, and their straw dry weight, spike length, plant height, number of tillers, number of grains, and thousand seed weight were measured and counted. As in Table I, the three transgenic strains all showed obvious reduction in lignin content, among which $\mathrm{C} 4 \mathrm{H}$ strain exhibited most significant lignin decrease, up to $9.35 \%$. Moreover, agronomic traits of this strain were the best compared to the other two strains. Therefore, according to the RNA interference of the two genes, transgenic strains with interference on $\mathrm{C} 4 \mathrm{H}$ gene resulted in sharpest lignin decline and minimal impact on agronomic traits.

TABLE I: AGRONOMIC TRAITS AND LIGNIN CONTENT OF TRANSGENIC RICE

\begin{tabular}{lllll}
\multicolumn{5}{c}{ PLANTS } \\
\hline \hline Material & CK & 4CL & 4CL & C4H \\
\hline Straw dry weight $(\mathrm{g})$ & 33.33 & 19.34 & 44.37 & 32.01 \\
Spike length $(\mathrm{cm})$ & 22.75 & 24.20 & 24.38 & 23.00 \\
Plant height $(\mathrm{cm})$ & 111.5 & 104.2 & 110.8 & 120.2 \\
Number of tillers & 9 & 7 & 12 & 11 \\
Number of grains & 1153 & 509 & 1023 & 1066 \\
Straw lignin content $(\%)$ & 14.00 & 10.17 & 12.20 & 9.35 \\
\hline \hline
\end{tabular}

CK MEANS CONTROL RICE

\section{B. Comparative Analysis on Field Growth Conditions of $T_{0}$ Generation Transgenic Rice Plant}

Fig. 1 is a contrast of photographs of $\mathrm{C} 4 \mathrm{H}, 4 \mathrm{CL}$, and C4HL transgenic rice plants and CK plant, which were randomly taken from rice harvest. It found out that 4CL rice developed worse than other strains, and its plant was short and small. There was no significant difference between $\mathrm{C} 4 \mathrm{H}$ and $\mathrm{C} 4 \mathrm{HL}$ transgenic varieties from $\mathrm{CK}$, and their plants of $\mathrm{C} 4 \mathrm{H}$ and $\mathrm{C} 4 \mathrm{HL}$ were even stronger than $\mathrm{CK}$.
According to the above figure, the roots of all the three genetically modified varieties are significantly more developed than the control plant. In addition, during the subsequent harvesting process, other single plants also exhibited a well-developed root system.

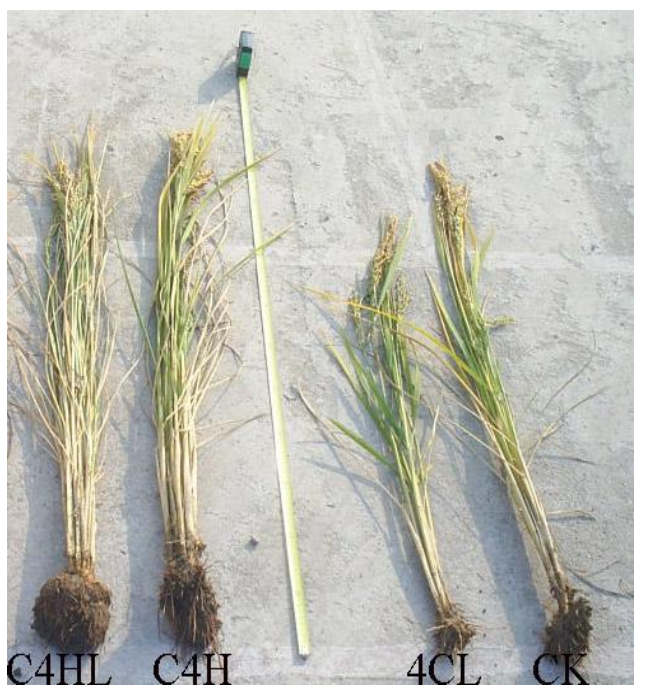

Fig. 1. Comparison of $\mathrm{C} 4 \mathrm{H}, 4 \mathrm{CL}$ and $\mathrm{C} 4 \mathrm{HL}$ transgenic rice plants with $\mathrm{CK}$.

\section{Semi-Quantitative RT-PCR on $T_{1}$ Transgenic Rice Plant}

In order to test the effectiveness of RNA interference, RNA were extracted from $T_{1}$ tender shoots for semi-quantitative RT-PCR detection of 4CL, C4H and C4HL gene expression. Results showed that there appeared segregation of character in the $\mathrm{T}_{1}$ generation and it complied with Mendel's laws; the expression of single-gene 4CL and $\mathrm{C} 4 \mathrm{H}$, and double-genge $\mathrm{C} 4 \mathrm{H}$ and $4 \mathrm{CL}$ in shoots of positive clone plants all showed decrease (Fig. 2, showing part of the results). Although expressions of the two single-genes and one double-gene in transgenic plant strains were different to each other, they were all lower than the untransformed plants. This proves that the gene silencing effect of constructed RNAi vectors is significant, but it varies from strains.

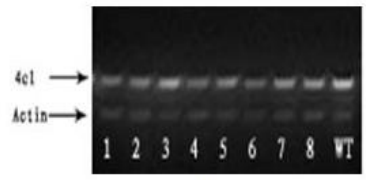

a

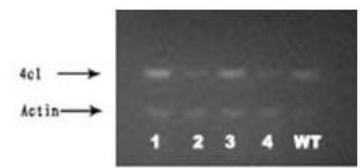

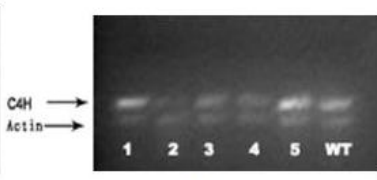

b

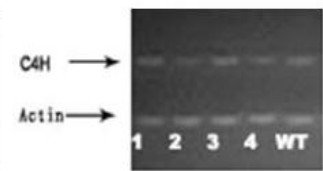

Fig. 2. Expression analysis of $4 \mathrm{CL}$ and $\mathrm{C} 4 \mathrm{H}$ genes in transgenic rice plants. a 4CL expression in RNAi 4CL rice. b 4CH expression in $\mathrm{RNAi} 4 \mathrm{CH}$ rice. c 4CL expression in RNAi 4CL AND 4CH rice. $\mathrm{d} 4 \mathrm{CH}$ expression in RNAi 4CL AND 4CH rice.

\section{DISCUSSION}

The premise of low-lignin transgenic rice application is that it should not harm the normal growth and development of rice, i.e. there should be no bad and slow growth, lodging 
or other results which will affect rice yield. According to the detection of the agronomic traits of $\mathrm{T}_{0}$ generation, although transgenic 4CL single-gene plants can significantly suppress lignin synthesis and reduce lignin content in the straw, it also inhibits growth seriously. All the indicators are significantly lower than those of non-transgenic varieties of the same strain. Worse still, lodging is prevalent, causing serious production decline. All these would be certain defects during application.

Based on straw lignin detection of $\mathrm{T}_{0}$ generation and semi-quantitative RT-PCR test on tender shoots of $T_{1}$ generation, it proves that the expression of these three genes is suppressed and lignin content in straw decreases. This basically agrees with related literatures on the analysis results of lignin and cellulose content in transgenic plants [7]. The reduction of lignin content in transgenic plants shows that the RNAi vectors into genes interfered normal RNA transcription or expression. However, generally speaking, repression and regulation of lignin gene can significantly reduce lignin content in transgenic plants, and meanwhile obtain $\mathrm{C} 4 \mathrm{H}$ gene which will not affect plant's normal growth. Accordingly, inhibition of $\mathrm{C} 4 \mathrm{H}$ gene expression would be an ideal way to improve timber or agricultural products, for it can reduce lignin content without harming the normal growth of plants. This study constructs transgenic carriers by RNAi to inhibit key enzymes in lignin synthesis in the rice plant straw, so as to relatively decrease lignin content in rice plant straw, increase cellulose content, and eventually provide high-quality raw materials for rice straw bioavailability.

\section{REFERENCES}

[1] J. G. Pettenati and D. Goffner, "Lignin genetic engineering revisited," Plant Science, vol. 145, pp. 51-65, 1999.

[2] M. Baucher, B. Monties, M. V. Montagu, and W. Boerjan, "Biosynthesis and genetic engineering of lignin," Critical Reviews in Plant Sciences, vol. 17, pp. 125-197, Feb. 1998.

[3] M. Baucher, C. Halpin, M. Petit-Conil, and W. Boerjan, "Lignin: genetic engineering and impact on pulp," Crit Rev Biochem Mol Biol, vol. 38, pp. 305-501, 2003.

[4] D. Miki, R. Itoh, and K. Shimamoto, "RNA silencing of single and multiple members in a gene family of rice," Plant Physiol, vol. 138, pp. 1903-1913, 2005.

[5] J. Raes, A. Rohde, J. H. Christensen, Y. V. Peer, and W. Boerjan, "Genome-wide characterization of the lignification toolbox in arabidopsis," Plant Physiol, vol. 133, pp. 1051-1071, 2003.

[6] Y. Hiei, T. Komari, and T. Kumashiro, "Efficient transformation of rice (Oryza sativa L.) mediated by agrobacterium and sequence analysis of the boundaries of the T-DNA," Plant J., vol. 6, pp. 271-282, 1994.

[7] M. Baucher, C. Halpin, M. P. Conil, and W. Boerjan, "Lignin:genetic engineering and impact on pulp," Crit Rev Biochem Mol Biol., vol. 38, pp. $305-501,2003$.

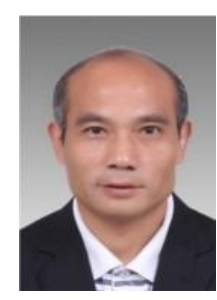

Xia Gengshou was born on October 15, 1968, in Jinyun Zhejiang, and he is now an associate professor. He graduated from Ningbo Agricultural Technology College in 1996, got Bachelor's degree in agronomy of China Agricultural University, got Bachelor's degree in agronomy of China Agricultural University in 2004.

$\mathrm{He}$ is mainly engaged in the application of biotechnology and resistance physiology research. He has hosted or participated in more than 10 projects, and published more than 30 academic papers.

Prof. Xia is a member of Zhejiang Plant Physiology Association, and Chinese Society for Ecological Economics Education Committee Association. 